\title{
Impacts of land use and land cover changes on surface energy and water balance in the Heihe River Basin of China, 2000-2010
}

\author{
Xiangzheng Deng ${ }^{\mathrm{a}, *}$, Qingling Shi ${ }^{\mathrm{a}, \mathrm{b}}$, Qian Zhang ${ }^{\mathrm{a}}$, Chenchen Shi ${ }^{\mathrm{c}}$, Fang Yin ${ }^{\mathrm{a}}$ \\ ${ }^{a}$ Center for Chinese Agricultural Policy, Institute of Geographic Sciences and Natural Resources Research, Chinese Academy of Sciences, Beijing 100101, China \\ ${ }^{\mathrm{b}}$ School of Economics, Fudan University, Shanghai 200433, China \\ ' State Key Laboratory of Water Environment Simulation, School of Environment, Beijing Normal University, Beijing 100875, China
}

\section{A R T I C L E I N F O}

\section{Article history:}

Received 6 August 2014

Received in revised form 7 January 2015

Accepted 9 January 2015

Available online 24 January 2015

\section{Keywords:}

LUCC

Water balance

Energy balance

WRF model

Heihe River Basin

\begin{abstract}
A B S T R A C T
It is well known that there are huge land use and land cover changes (LUCC) all over the world in recent decades, and plenty of ensuing effect appeared on the energy and water balance. This study aims to analyze the impacts of land use and land cover changes on the energy and water balance in the Heihe River Basin of China during 2000-2010, and four key study sites with representative hydrological stations and dramatic LUCC in the past decades were selected to illustrate the responses of the energy and water balance to LUCC. First, LUCC of the Heihe River Basin from 2000 to 2010 was analyzed based on the interpretation of remote sensing images. Then a series of indicators of the energy and water balances were simulated with the Weather Research and Forecasting (WRF) model and corresponding land use and land cover data. Thereafter the impacts of LUCC on the surface energy and water balance were detected and analyzed. The spatial-temporal variance of the impacts of LUCC on energy and water balance in a typical arid inland river basin was specifically presented in following analysis. The results show that different land use/cover conversions result in various energy balances. During this process, the most significant impacts on surface energy balance occurred when grassland was converted to barren or sparsely vegetated land. As for water balance, the impact is measured with variations of precipitation, runoff and evapotranspiration induced by LUCC, which were also remarkable, although seasonal trends of the effects are similar among various land use/cover conversions during 2000-2010. At last, policy suggestions, e.g., shifting the water balance by LUCC to improve the water management, are given to conclude this study.
\end{abstract}

(c) 2015 Elsevier Ltd. All rights reserved.

\section{Introduction}

There have been tremendous changes in global land use and land cover in the past decades (Foley et al., 2005; Lambin and Meyfroidt, 2011), especially in countries with rapid development, such as China (Deng et al., 2006; Seto et al., 2011). Land use and land cover changes (LUCC), which are expected to continue in the future, have enormous influence on global and regional climate and water balance (Anav et al., 2010; Kueppers and Snyder, 2012; Deng et al., 2013). In this sense, the impacts of LUCC on global and regional climate change have attracted great attention (Chen et al., 2005; Seneviratne et al., 2006). For example, recent studies have shown that anthropogenic LUCC have dramatically altered the earth's land surface (Ramankutty et al., 2008; Margono et al., 2012) and played a vital role in reshaping the global patterns of energy and/or water balances (Chen et al., 2005; Seneviratne

\footnotetext{
* Corresponding author. Tel.: +86 10 64888385; fax: +86 1064856533 .

E-mail address: dengxz.ccap@igsnrr.ac.cn (X. Deng).
}

et al., 2006). Previous studies showed that the large-scale land use/cover dynamics exerted huge impacts on the surface energy and water balance through biochemical and biophysical processes (Twine et al., 2004; Ardli and Wolff, 2009; Jiang et al., 2011; Liu and Deng, 2011; Deng et al., 2012; Huang et al., 2013). Besides, some research indicated that surface roughness, albedo and other properties, which affect exchanges of water and energy between the land surface and the atmosphere, will be altered by the conversion of natural ecosystems to irrigated agriculture, leading to various changes of the surface energy and net radiation in different seasons (Kueppers and Snyder, 2012). In addition, some studies of the urban expansion showed that the conversion to built-up area resulted in a rapid increase of impervious surface area, leading to more water flows over impervious surfaces or through runoff networks, which consequently increased the speed of flows to the receiving water bodies and resulted in more significant urban heat island effects (Oke, 1982; Gregory et al., 2006; Yadav et al., 2012). In summary, most of the previous studies focused on the impacts of a certain kind of land use conversion on the energy 
and water balance in a certain region. In this study, we not only refine the land use categories but also focus on all kinds of land use conversions.

There have been several models to quantify the impacts of LUCC on surface energy and water balances (Rwasoka et al., 2011), which can be generally divided into two categories. One is based on the hydrological models or regional climate models, such as International Center for Theoretical Physics (ICTP), Regional Climate (RegCM3) model (Kueppers and Snyder, 2012), Davis Regional Climate (DRCM) model (Kanamaru and Kanamitsu, 2008), and Soil and Water Assessment Tool (SWAT) model (Schilling et al., 2008). It is quite popular and mature to separately analyze the water balance with hydrological models and analyze the energy balance with regional climate models (Jothityangkoon et al., 2001; Shindell et al., 2001; Döll et al., 2003; Gerten et al., 2004; Fettweis, 2007). However, not all of these studies quantified the impacts of LUCC on energy and water balance from a comprehensive view (Sakai et al., 2004; Twine et al., 2004; Schilling et al., 2008). The other is based on the combination of land use simulation model with hydrological models or regional climate models, such as the combination of Integrated Biosphere Simulator (IBIS) model and Hydrologic routing model (HYDRA) (Lenters et al., 2000), and the combination of Simple Biosphere Model (SiB2). The basic thought of the latter category is to firstly simulate the LUCC with the land use simulation model and then simulate the energy balance and water balance based on the simulated LUCC (Bormann et al., 2007; Fohrer et al., 2005). However, there is a major technical challenge in the latter category, i.e., the transformation of parameters (Romanowicz et al., 2005; Li et al., 2007).

It is more persuasive to analyze the impacts of LUCC with the real historical land use/cover data since it is feasible to verify the simulated results with the observed records. In this study, the impacts of LUCC on the energy and water balance have analyzed with the historical land use/cover data used as the input parameters of the WRF model as follows. First, we analyzed the land use/cover dynamics in the Heihe River Basin (HRB) from 2000 to 2010, and four key study sites within HRB were selected, which have experienced dramatic LUCC and possess representative hydrological stations. Then two sets of simulation schemes were designed to analyze the changes of energy and water balances with the WRF model. Thereafter, the results simulated with the WRF model were compared with the observation records from hydrological stations to verify the simulation capability of WRF model. The simulation results can provide a better understanding of the influencing factors of water and energy balances in the HRB and assist local managers in formulating proper land use planning to offset the LUCC-induced negative impacts on the surface energy and water balance.

\section{Study area and data}

\subsection{Study area}

HRB is the second largest inland river basin of China, covering an area of $143,000 \mathrm{~km}^{2}$. It is located in the northwest region of China $\left(90^{\circ} \mathrm{E}-102^{\circ} \mathrm{E}, 37^{\circ} 50^{\prime} \mathrm{N}-42^{\circ} 40^{\prime} \mathrm{N}\right)$ and expands across Qinghai Province, Gansu Province and Inner Mongolia Autonomous Region (Fig. 1). The Qilian Mountains lie in the southwest part of this basin, and Badain Jaran Desert lies in the east part, with the elevation ranging from $980 \mathrm{~m}$ to approximately $4000 \mathrm{~m}$. The HRB belongs to the semi-arid and sub-humid temperate continental monsoon climate zone, with significant temperature variation among seasons. Besides, the precipitation and evaporation show significant spatiotemporal heterogeneity under the influence of geographic factors and atmospheric circulation. Therefore, we

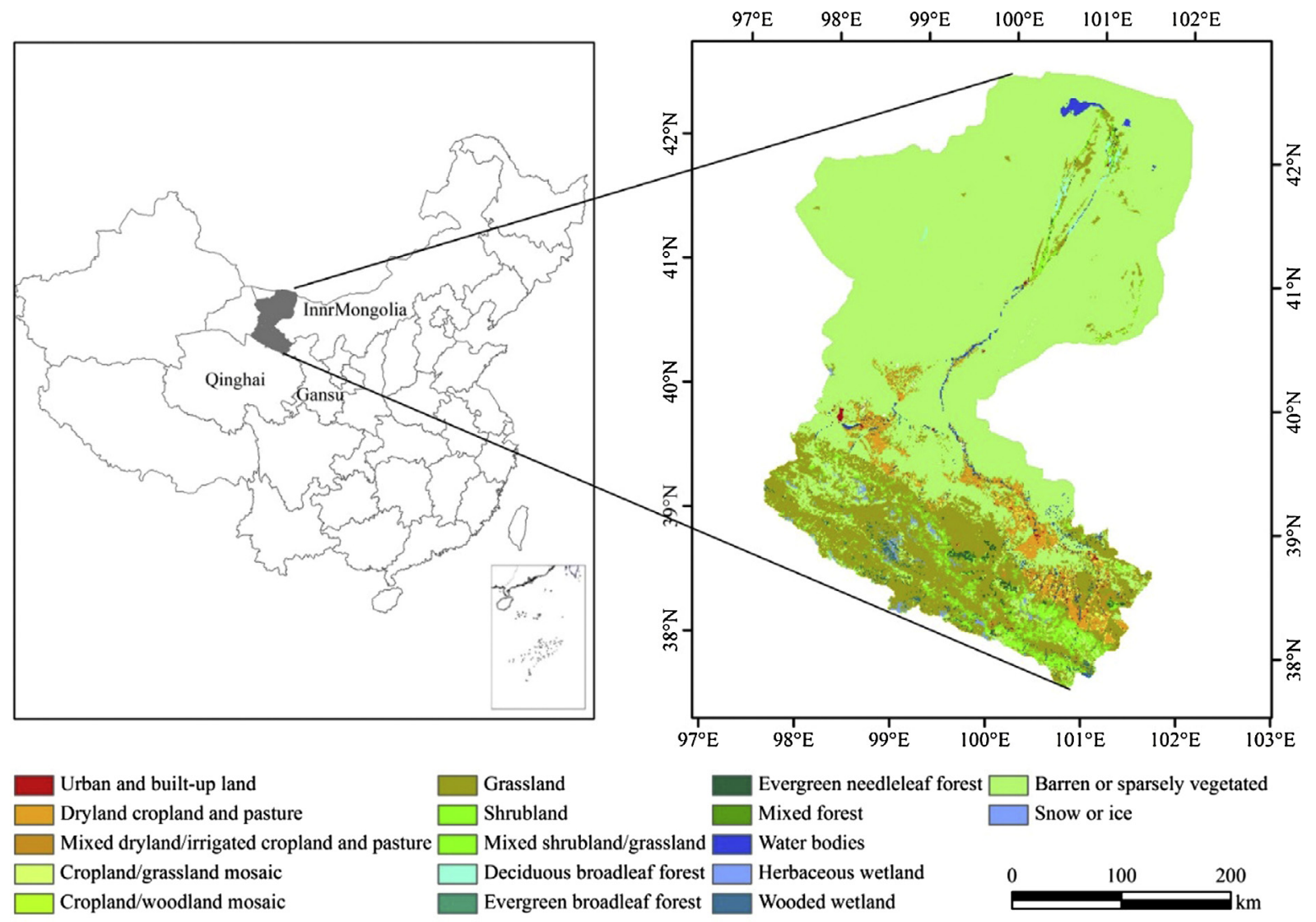

Fig. 1. Location and land use and land cover in 2010 of the HRB. Note: Land use/cover codes are listed in Table 1. 
Table 1

Land use/cover types of USGS land classification system.

\begin{tabular}{lll}
\hline Code & Land use/cover & Description \\
\hline 100 & UBL & Urban and built-up land \\
211 & DCP & Dryland Cropland and pasture \\
212 & ICP & Irrigated Cropland and pasture \\
213 & MCP & Mixed dryland/Irrigated Cropland and pasture \\
280 & CGM & Cropland/grassland mosaic \\
290 & CWM & Cropland/woodland mosaic \\
311 & GL & Grassland \\
321 & SL & Shrubland \\
330 & MSG & Mixed shrubland/grassland \\
332 & SA & Savanna \\
411 & DBF & Deciduous broadleaf forest \\
412 & DNF & Deciduous needleleaf forest \\
421 & EBF & Evergreen broadleaf forest \\
422 & ENF & Evergreen needleleaf forest \\
430 & MF & Mixed forest \\
500 & WB & Water bodies \\
620 & HW & Herbaceous wetland \\
610 & WW & Wooded wetland \\
770 & BSV & Barren or sparsely vegetated \\
820 & HT & Herbaceous tundra \\
810 & WT & Wooded tundra \\
850 & MT & Mixed tundra \\
830 & BGT & Bare ground tundra \\
900 & SI & Snow or ice \\
\hline
\end{tabular}

chose this specific study site to explore the impact of LUCC in energy and water balance. In addition, the whole basin is divided into the upper, middle and lower reaches, which are featured by different natural conditions and social economic development status. The upper reach is the water source area, where the mean runoff coefficient is up to 0.85 and the cumulative proportion of runoff reach to $68 \%$. The middle reach is the water consumption zone, where most of the land has been reclaimed for oasis agriculture, and it accounts for $95 \%$ of the cultivated land, $91 \%$ of the population and more than $80 \%$ of the GDP of the whole HRB. The lower reach is the tail-end zone, with a huge evaporation capacity and very fragile ecological environment.

\subsection{Data source and handling}

Three kinds of data are used in this study, including land use/ cover data, climate forcing data, surface energy and hydrological data. The $1 \mathrm{~km}$ resolution land use/cover data, which are obtained from the interpretation of remote sensing images, are provided by Data Center for Resources and Environmental Sciences, Chinese academy of sciences (CAS) (Liu et al., 2009; Wu et al., 2013). The land use/cover of the U.S. Geological Survey (USGS) classification system has been used in this study (Table 1) since it has been widely used in the simulation with modern land surface and distributed hydrological/ecological models (Chen and Dudhia, 2001; Wu et al., 2013). Besides, the geographically segmented (GEOG) climate forcing data used in this study, which are updated every $6 \mathrm{~h}$, were downloaded from NCEP FNL (Final) Operational Global Analysis (http://rda.ucar.edu/datasets/ds083.0/). This dataset with the spatial resolution of $1^{\circ} \times 1^{\circ}$ and the vertical height of 27 layers, has been constructed and updated since July 1999 with the data assimilation of observation data (e.g., the remote sensing data and ground-based observation data). The time period of the climate forcing data was truncated from January 2000 to December 2010 in this study. Both the climate forcing data and land use/ cover data were used as the input data of the WRF model. In addition, the climate data, energy flux data and hydrologic records were obtained from the hydrological stations and meteorological stations. The $20 \mathrm{~km} \times 20 \mathrm{~km}$ resolution temperature data were obtained by interpolating the monthly average temperature data
Table 2

The main land use/cover changes in the HRB, 2000-2010.

\begin{tabular}{|c|c|c|c|c|c|}
\hline $\begin{array}{l}\text { Land } \\
\text { use/ } \\
\text { cover } \\
\text { in } \\
2000\end{array}$ & $\begin{array}{l}\text { Land } \\
\text { use/ } \\
\text { cover } \\
\text { in } \\
2010\end{array}$ & $\begin{array}{l}\text { Area } \\
\text { in } \\
2000 \\
\left(\mathrm{~km}^{2}\right)\end{array}$ & $\begin{array}{l}\text { Conversion } \\
\text { area }\left(\mathrm{km}^{2}\right)\end{array}$ & $\begin{array}{l}\text { Conversion as } \\
\text { percentage of } \\
\text { area in } 2000 \\
(\%)\end{array}$ & $\begin{array}{l}\text { Conversion as } \\
\text { percentage of } \\
\text { total conversion } \\
\text { area (\%) }\end{array}$ \\
\hline GL & BSV & 22,083 & 1529 & 6.9 & 20.0 \\
\hline GL & SL & 22,083 & 1029 & 4.7 & 13.5 \\
\hline BSV & DCP & 91,798 & 853 & 0.9 & 11.2 \\
\hline MSG & SL & 1536 & 631 & 41.1 & 8.3 \\
\hline CGM & DCP & 711 & 529 & 74.4 & 6.9 \\
\hline BSV & SL & 91,798 & 525 & 0.6 & 6.9 \\
\hline MCP & BSV & 2892 & 500 & 17.3 & 6.5 \\
\hline
\end{tabular}

Note: Land use/cover codes are listed in Table 1.

derived from the 57 meteorological stations in the HRB with the Kriging interpolation method. The historical meteorological data in 2000 were put into in the WRF model. To validate the simulation accuracy, we collect the observed records on climatic data, energy flux and hydrological data in 2010 from the certain hydrological and meteorological stations and compared them with the results simulated with the WRF model.

There are 17 types of land use/cover in HRB according to the USGS classification, indicating complex land surface characteristics. In particular, the barren or sparsely vegetated land cover accounts for more than $70 \%$ of the total area, approximately $20 \%$ of the land is covered by grassland, with the rest being other types. Previous study shows that cultivated land, saline and alkaline land, and built-up area increased before 2000, while the forestry area, grassland, river and glacier decreased (Deng et al., 2010). Besides, the land use/cover has changed dramatically after 2000. The LUCC during 2000-2010 was analyzed by calculating the transition matrix in this study, and Table 2 shows the major land use/cover changes during 2000-2010 in the HRB.

Since there is great difference in the energy conditions and water conditions among the upper, middle and lower reaches of the HRB, four case study areas (Fig. $2 \mathrm{~h}$ ) were selected for a further analysis, where there are representative hydrological stations. The selected representative hydrological stations include Qilian Station (S1) in the upper reaches, Liqiao Reservoir (S2) and Jiayuguan Station (S3) in the middle reaches, and the Langxin Mountain Station (S4) in the lower reaches (Fig. 2). Besides, the selected case study areas are characterized by different types of LUCC. In the case study area in the upper reaches, a lot of grasslands have changed into shrubland due to the implementation of soil and water conservation policies. While there are mainly two types of LUCC in the middle reaches. For example, in the case study area with $\mathrm{S} 2$, plenty of cropland/grassland mosaic land changed into dry cropland, while in the case study area with S3, the water area increased significantly due to conversion from the barren or sparsely vegetated land. By comparison, the case study area with S4 in the lower reaches is mainly characterized by the conversion from grasslands to barren or sparsely vegetated land (Table 3 ).

\section{Method}

Observational analysis and model-based simulation are both adopted in this study. Firstly, we conducted data analysis of the HRB, where Geographic Information System technologies are frequently used to process and analyze data. This step is the basis of the simulation process that followed. Then under certain designing of simulation and the prepared input parameters, model-based simulation could be done accordingly, the output variables could be obtained to identify the influence of the two kinds of balances caused by land use/cover changes. The main method used in this 


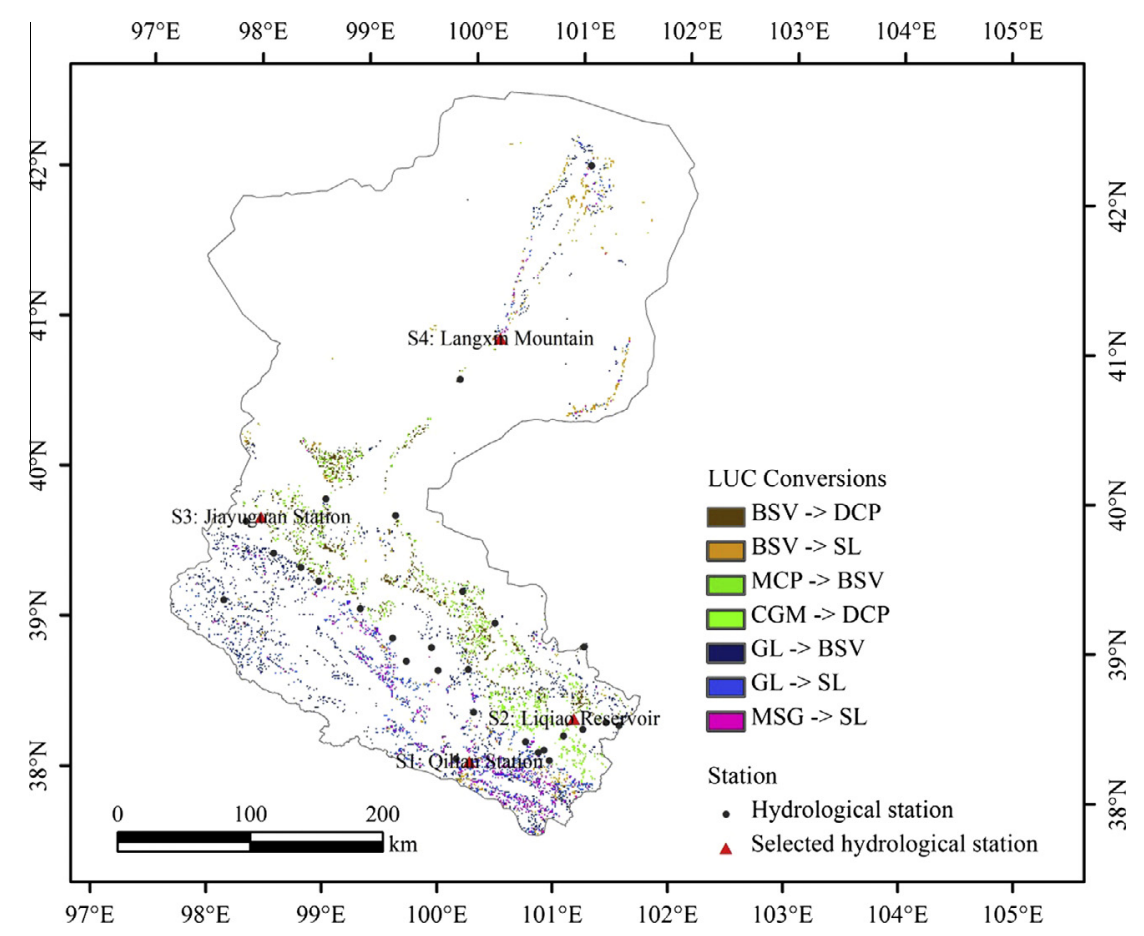

Fig. 2. Major LUCC in the HRB (2000-2010) and the hydrological stations.

Table 3

LUCC matrix of the for key study sites in the HRB during 2000-2010.

\begin{tabular}{|c|c|c|c|}
\hline Station & Name & LULC in 2000 & LULC in 2010 \\
\hline S1 & Qilian Station & Grassland & Shrubland \\
\hline S2 & Liqiao Reservoir & Cropland/grassland mosaic land & Dryland Cropland and pasture \\
\hline S3 & Jiayuguan Station & Barren or sparsely vegetated land & Water area \\
\hline S4 & Langxin Mountain & Grassland & Barren or sparsely vegetated land \\
\hline
\end{tabular}

step is the WRF model. The two steps mentioned above are both designed to serve the subsequent analysis phase, which is also the most important part of the study. Next by analyzing the output variables of the simulation according to certain balance equations, general and empirical interpretation could be done in regard to the impact of the two kinds of balance caused by LUCC.

\subsection{WRF model and simulation schemes}

The analysis of the energy balance and water balance in the HRB was based on the simulation with the WRF model, a regional climate model that has been widely used in the global climatic studies (Seneviratne et al., 2006; Ramankutty et al., 2008; Anav et al., 2010; Jiang et al., 2011; Margono et al., 2012). The WRF model is a meso-scale numerical weather prediction system designed to meet the needs of both atmospheric research and operational forecasting. Besides, there are two dynamical core versions of WRF, including the Advanced Research WRF (ARW) and the WRF-NMM (NMM), and the former one was adopted in this study. The ARW module includes the Preprocessing System (WPS), main program and postprocessor, and Post processing System, it provides many physical parameterization schemes and has strong robustness for predicting the climate change with various parameters such as the temperature, precipitation, radiation and heat flux.

Two sets of tests were designed and performed in this study, namely the control test and the sensitivity test. The two tests differ in the land cover types of the underlying surface, the land cover data of the year 2000 served as a reference in the control test, while that of the year 2010 were included in the sensitivity test. The input parameters and parameterization scheme of the physical processes except the land cover data were the same in the two tests in order to analyze the impacts of LUCC on the energy and water balances. The two tests were implemented with the same climate forcing data between October 2008 and December 2010. The simulation period of the control test ranged from January 2000 to December 2010, and the land cover data of the year 2000 were used as underlying surface data. While the simulation period in the sensitivity test ranged from January 2010 to December 2010, with the land cover data of the year 2010 used as the underlying surface data. The experiment was designed in this way to eliminate the influence of the climate forcing data and simultaneously focus on the impacts of LUCC on the surface energy balance and the water balance.

\subsection{Energy balance and water balance}

The WRF model was used to simulate the change of the parameters to represent the energy balance and water balance, and then the energy balance equation and the water balance equation were used to analyze the impacts of LUCC on the energy and water balance. The following simplified equations were used to examine the 
energy balance (Seto et al., 2011). It should be noted that the energy balance generally only refers to the surface energy balance.

$H+E=R n-G$

$H=\rho c_{p} K_{h} \Delta t / \Delta z$

$L=(1-\Upsilon) \rho c_{p} K_{w} \Delta e / \Delta z$

$\beta=\frac{H}{E}=\Upsilon \Delta t / \Delta e$

where $R n$ is the net energy flux at the interface, representing the total energy absorbed by the ecosystem $\left(\mathrm{W} / \mathrm{m}^{2}\right)$, which is redistributed into $H, E$ and $G$; $H$ refers to the sensible heat, $E$ is the latent heat $\left(\mathrm{W} / \mathrm{m}^{2}\right), G$ refers to the soil heat flux $\left(\mathrm{W} / \mathrm{m}^{2}\right), \Upsilon$ is wet and dry bulb constant, $K_{h}$ and $K_{w}$ are the diffusion coefficients of the sensible heat and the latent heat, respectively, and it is generally assumed that $K_{h}=K_{w}$ since the two exchange processes rate are similar; $\Delta t, \Delta e, \Delta z$ are the temperature difference, pressure of water vapor difference and altitude intercept of two heights, respectively; $\rho$ is the density, $\rho c_{p}$ means the heat a subject needs when its temperature rises by one degree per volume; $\beta$ is the ratio of $H$ to $E$, which is called the Bowen ratio. The change of Bowen ratio indicates the variation of evaporation and reflection ability, which are directly associated with LUCC.

It is necessary to specify some terms with regard to the water balance at first. Altogether, there are three types of water balance, i.e., the natural water cycle balance which is characterized by precipitation-runoff balance, social water cycle balance and the balance between the supply and demand of water resources. In this study, we focused on the natural water cycle balance, which is also the foundation for analyzing the social water cycle as well as the supply and demand of water resources at the watershed scale. In some sense, the analysis of the natural water cycle balance is sort of analysis of the water yield cycle balance, which is the relationship among precipitation, evaporation capacity and runoff in a watershed. The water balance in a closed watershed is expressed as follows if the change in water storage and inter-basin water transfer were neglected (Halihan et al., 1998; Sahu et al., 2013).

$P-E T-R=\frac{d W}{d t}-U$

where $P$ is the precipitation of the watershed in the period $(\mathrm{mm} /$ day), ET is the total evapotranspiration of the watershed in a period, including water surface evapotranspiration, soil evapotranspiration, vegetation transpiration and phreatic water evaporation $(\mathrm{mm}) ; R$ is the total runoff of the watershed export section in a period, which includes surface runoff and subsurface runoff $(\mathrm{mm}) ; W$ is the total surface water volume, including soil moisture, snow and groundwater ( $\mathrm{mm})$, and $U$ is the climatological soil moisture nudging term used in the NCEP/NCAR reanalysis, and $\frac{d W}{d t}$ refers to the variable quantity of water storage of the watershed in the period $(\mathrm{mm})$. Note that $U$ is a source term (positive denoting addition of water to the soil) and that $U=0$ in the simulations. Also, although changes in the groundwater level from the lowest layer into runoff are included in $\frac{d W}{d t}$ (in the observations), we did not pay much attention to the groundwater. In addition, the water withdrawal process of the socioeconomic system has been taken into account in this analysis.
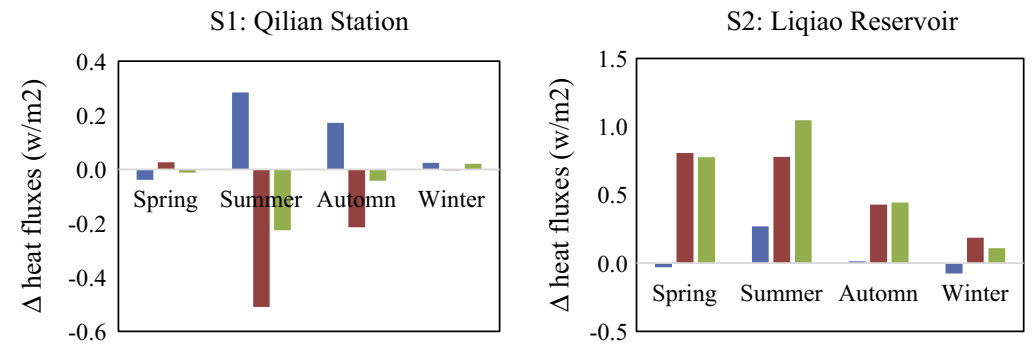

S3: Jiayuguan Station
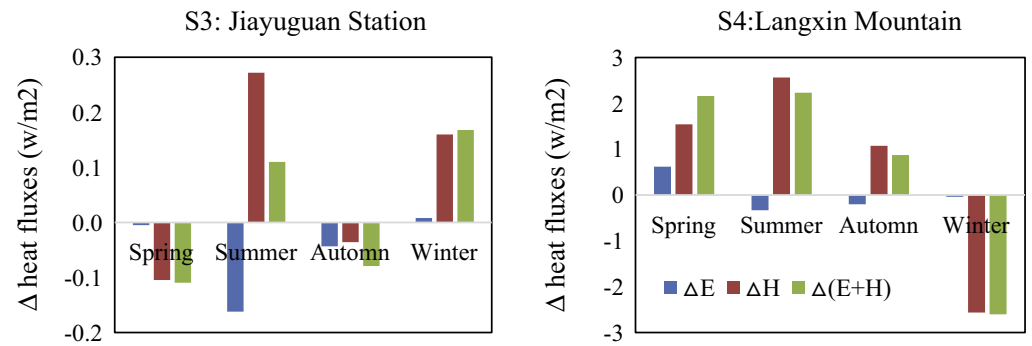

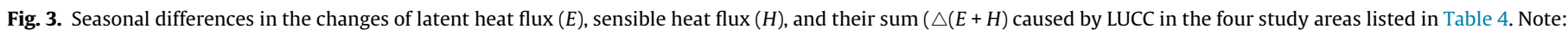

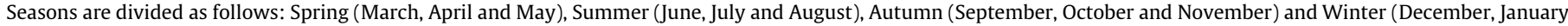
and February).

Table 4

Seasonal differences in the changes of Bowen ratio caused by LUCC in the four case study areas listed in Table 3.

\begin{tabular}{|c|c|c|c|c|c|c|c|c|}
\hline & \multicolumn{2}{|l|}{$\mathrm{S} 1$} & \multicolumn{2}{|l|}{$\mathrm{S} 2$} & \multicolumn{2}{|l|}{ S3 } & \multicolumn{2}{|l|}{ S4 } \\
\hline & Control test & Sensitivity Test & Control Test & Sensitivity test & Control test & Sensitivity test & Control test & Sensitivity test \\
\hline Spring & 5.83 & 5.56 & 6.23 & 6.18 & 11.45 & 11.72 & 17.78 & 17.74 \\
\hline Summer & 18.43 & 17.66 & 24.33 & 24.48 & 31.11 & 30.48 & 43.78 & 43.74 \\
\hline Autumn & 7.7 & 7.99 & 13.89 & 13.53 & 20.69 & 20.83 & 32.07 & 32.94 \\
\hline Winter & 4.48 & 4.32 & 7 & 6.83 & 25.03 & 24.79 & 71.49 & 72.05 \\
\hline Mean & 9.11 & 8.88 & 12.86 & 12.76 & 22.07 & 21.96 & 41.28 & 41.62 \\
\hline
\end{tabular}




\section{The impact of LUCC on surface energy}

The simulation results indicate that the LUCC exerted significant impacts on the energy balance in the study area. For example, in S4 (Fig. 3), the significant increase of albedo, which was generally associated with the conversion of grassland to barren or sparsely vegetated land, increased the net energy in regions with high vegetation coverage. Besides, the change in the net energy flux affected not only the magnitude of all fluxes, but also the partitioning of energy into different surface fluxes in different seasons. For example, the simulation results in S4 showed that the sensible heat fluxes decreased in winter and increased in other seasons, while the latent heat flux only experienced a slight increase in spring and decreased in summer and autumn (Fig. 3, S4). Land cover of S1 in 2000 was similar to that of S4, but the vegetation coverage of S1 increased slightly during the simulation period, resulting in slight decline of sensible heat flux and increase of latent heat flux in summer and autumn. Nevertheless, there was minor change of the vegetation coverage in S1 in spring and winter, which are not the growing seasons of vegetation, and as a result there was minor change in both the sensible and latent heat fluxes in these two seasons (Fig. 3, S1). A lot of cropland/grassland mosaic land changed into dryland Cropland and pasture in S2, which is a drying reservoir, and as a result the sensible heat flux increased, but there was not significant change in the latent heat flux (Fig. 3, S2). The dominant LUCC of S3 was similar to that of S1, i.e., the conversion from Barren or sparsely vegetated land into water area, and the change of the energy balance in S3 was also similar to that of S1, with only slight change all the year round (Fig. 3, S3).

The annual mean Bowen ratios in S1, S2 and S3 in the sensitivity test $(8.88,12.76$, and 21.96$)$ are slightly lower than that in the control test $(9.11,12.86$, and 22.07), while the situation in S4 in on the contrary, where the annual mean Bowen ratio in the sensitivity test is 0.34 higher than that in the control test (Table 4). The Bowen ratio is the ratio of $H$ to $E$, and its change indicates the variation of evaporation and reflection ability, which are directly associated with LUCC (Table 3). As S1, S2 and S3 were all characterized by the conversion from land types with low evaporation and high reflection to land types with high evaporation and low reflection, these areas demonstrated the same changing pattern in the Bowen ratio. By comparison, the LUCC of S4 was from high evaporation and low reflection to low evaporation and high reflection, which led to the different change in the Bowen ratio.

As for the seasonal variation, there were similar changing trends of the Bowen ratio in the S1, S2 and S3 in both the sensitivity test and the control test, which was higher in summer and lower in winter and moderate in spring and autumn. By comparison, the highest Bowen ratios appeared in winter and the lowest ones appeared in spring in S4 in both the sensitivity test and the control test. Besides, in all of the four areas, the evaporation and reflection ability were generally higher in summer and lower in winter. However, in the first three areas, the net decrease of evaporation in winter was more significant than the net decrease of reflection in summer, while S4 demonstrated the opposite trend. Consequently, there were certain effects of LUCC on the Bowen ratio, but the seasonal variation trends of the Bowen ratio nearly remained unchanged.

\section{The impact of LUCC on water balance}

The simulated water budget components include the monthly changes of precipitation $(P)$, evapotranspiration $(E T)$, runoff $(R)$, the difference between precipitation and evapotranspiration $(P-$ $E T)$ and the surface water storage terms $(P-E T-R=d W / d t-U)$. The simulation results indicate that $P, E T$ and $R$ in all of the four (a) $\mathrm{P}(\mathrm{mm} /$ month)

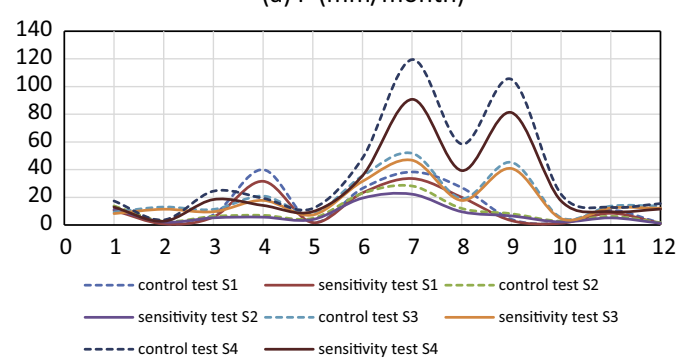

(b) ET (mm/month)

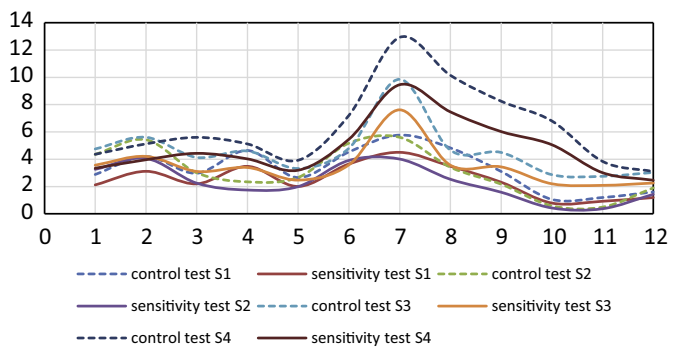

(c) R / (mm/month)

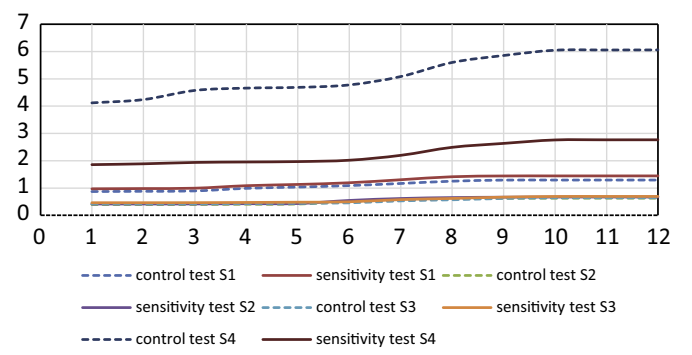

(d) P-ET / (mm/month)

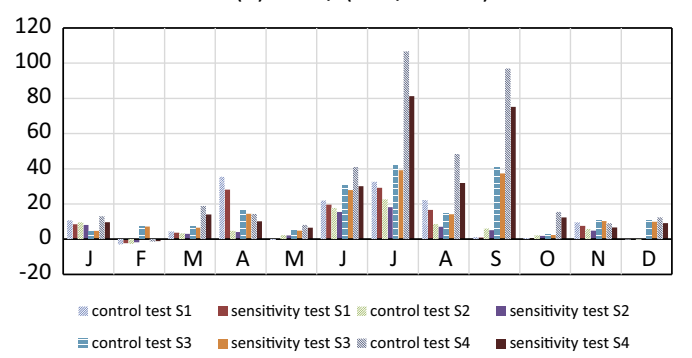

(e) P-ET-R=(dW/dt-U) / (mm/month)

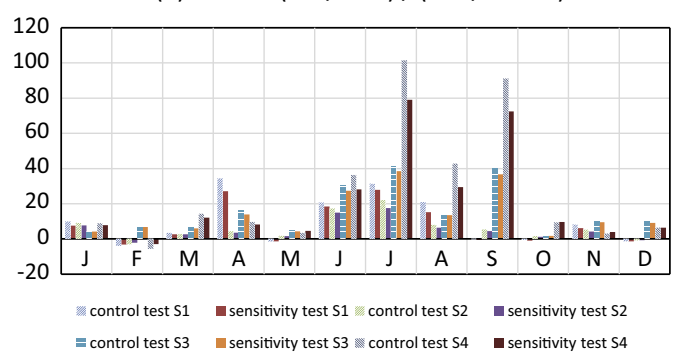

Fig. 4. Simulated $P$ (a), $E T$ (b), $R$ (c), $P-E T$ (d) and $P-E T-R=(d W / d t-U)$ (e) in the control test and the sensitivity test of the four study areas. Note: Simulation results without LUCC refers to the simulation based on the LUCC data of the year 2000, whiles those with LUCC means the simulation are based on the LUCC data of the year 2010.

case study areas showed obvious seasonal variation (Fig. 4a-c), with a general similar variation trend of $P$ in two tests, but their 
values were different between the two tests, which showed the impacts of LUCC on precipitation, evapotranspiration and runoff. Meanwhile, the simulated $P-E$ curves in four case study areas showed a distinct seasonal cycle, with precipitation exceeding evapotranspiration (Fig. 4d). The surface water storage terms ( $P-$ $E T-R$ ) are depicted with the $P-E T-R$ curve (Fig. $4 \mathrm{e}$ ), which also showed significant seasonal variation in both the sensitivity and control tests. The $P-E T-R$ values in the sensitivity test are higher than that in the control test in the four key study sites, which indicated corresponding higher surface water storage in different degree is caused by LUCC in these areas.

Fig. 4 illustrates the simulation results of water budget components in the four case study areas in the sensitivity test and the control test, the differences between which are considered as the impacts of LUCC on the water balance. In S1 in the river source area in Qilian Mountain, there is obvious seasonal variation of P in both tests, with the peak appearing in April when the snow starts to melt. The runoff will increase in S1 due to the increased vegetation coverage rate, which leads to more rainfall and decline of evapotranspiration. The $P-E T$ curve and the $P-E T-R$ curve are quite similar, with the values greater than annual mean water storage during April and from June to August. Meanwhile, the monthly average water storage in the sensitivity test is higher than that in the control test. In S2, both the precipitation and evapotranspiration decline due to the LUCC, however, the overall runoff increases. The $P-E$ curve also shows notable seasonal variation, with the highest value occurring during June and August in both tests. The $P-E T-R$ curve is very similar to the $P-E$ curve, with higher than annual mean storage from June to August in both of the two tests, but the water storage value is higher in the sensitivity test than that in the control test. In S3, the precipitation decreases slightly due to LUCC, which further leads to the decline of evapotranspiration. Meanwhile, the runoff value is higher in the sensitivity test than that in the control test, which exactly reveals the increasing effects LUCC on the surface runoff in this area. Then it is self-evident that the $P-E$ value in the sensitivity test is higher than it is in the control test. The $P-E T-R$ curves in both tests show that insufficient water is stored between October and May, and excessive water is stored between June and September. However, the monthly water storage in the sensitivity test is more than that in
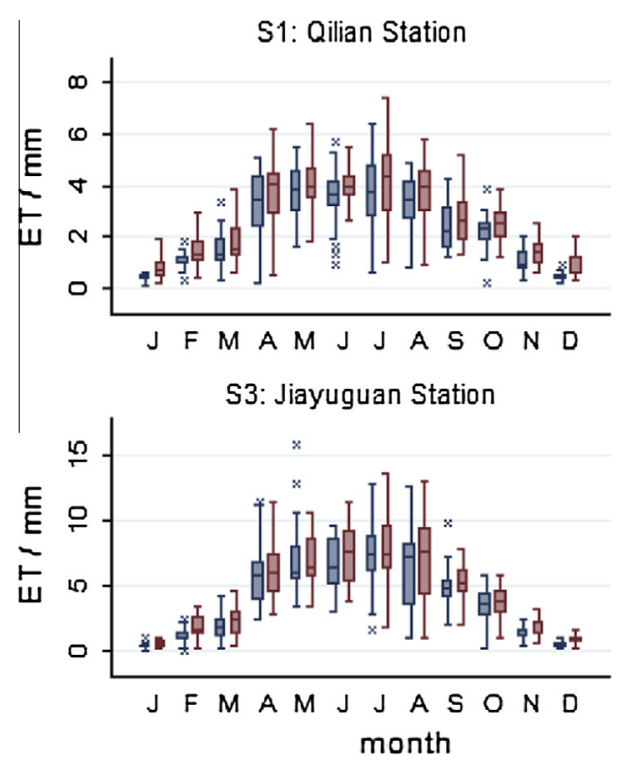

the control test, which indicates that the total water storage increases due to LUCC in this area. In S4, the simulation results indicate that the precipitation and evapotranspiration both decline due to the decreased vegetation coverage, so as to the runoff increases since there is less water that is absorbed by soil or gets into the underground water. Consequently, the monthly average water storage increase slightly due to LUCC in this study area. Besides, the most significant changes occur during June and September. Meanwhile, the variation trends of $P, E T, R, P-E T$ and $P-$ $E T-R$ are quite similar in S4 in the two tests.

The results of this study are kept consistent with some previous research in the same study area (Gao et al., 2008), i.e., there are obvious seasonal changing trends of the surface energy balance and water balance. Besides, the general conclusions about the impacts of LUCC on energy and water balance in this study are similar to that of previous similar research that has taken LUCC into account (Boulain et al., 2009; Ramier et al., 2009; van der Meijden et al., 2010). However, the results of this study differ from previous research due to the difference in the study areas and the classification system of land use and land cover. For example, one empirical study in USA concludes that the runoff and ET decreased when the grassland changed into crop land (Sun et al., 2010), which is consistent with the results of this study; however, their study indicates the heat flux increased all year round due to land use change, which is different from the results of this study. Simulation results suggested that it will take a long time to restore the ecological environment and improve the water and soil conservation in the HRB. Therefore, this study supports the notion that it is much easier to destroy an ecosystem than to restore it, which raises the alarm for local land managers.

Fig. 5 shows the average daily observation value and simulated value of evapotranspiration. The simulated values of ET are larger than the observation values in the Langxin Mountain station (S4) covered by high quality grassland, where the largest ET occurs (Fig. 5). While in the Qilian Station (S1) where ET is the lowest among these four stations, the simulated value of ET is a little higher than the observation values, even though there is some grassland and it belongs to alpine meadow. Besides, Fig. 5 shows that ET will fluctuate more drastically in Liqiao Reservoir (S2), especially during April and August when it is the growing season
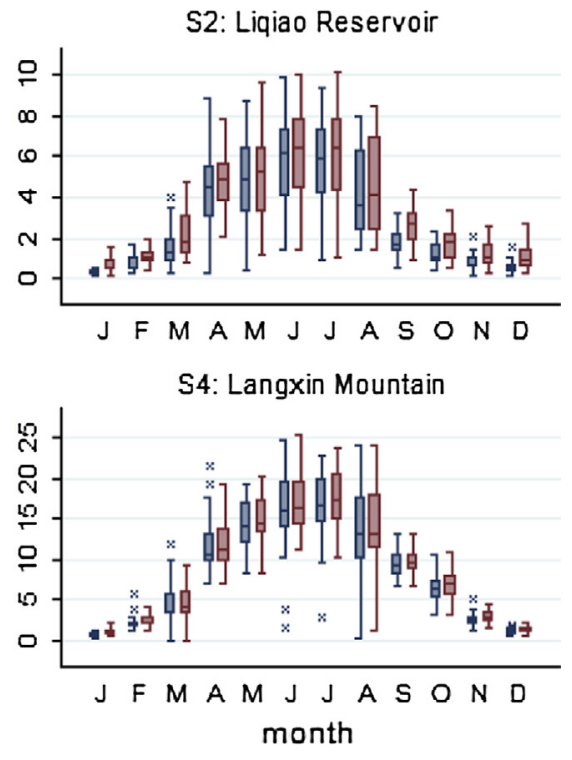

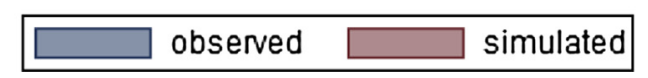

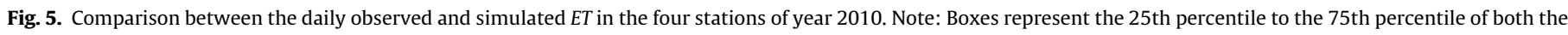
observed records and simulated values of $E T$, the lines include the upper adjacent value to the lower adjacent value, and the cross means the outside values. 
of vegetation. Overall, the simulated ET responds well to the observation records, indicating that the simulation method is reliable. However, it is still necessary to take more factors into consideration when simulating and analyzing the impacts of LUCC on the surface energy and water balance since the energy balance and water balance are complex processes that are related to the atmosphere and the soil system. For example, the groundwater circulation is an important component in the water balance, and it should be considered in the simulation scheme in the future.

\section{Conclusions}

This study explored the impacts of LUCC on the surface energy and water balance in the HRB during 2000-2010 based on the simulation with the WRF model. LUCC during 2000-2010 was first analyzed, and the dominant LUCC types were identified, according to which four typical case study areas were selected. Then the climate change was simulated with the WRF model on the basis of the land use/cover data in 2000 and 2010. Simulation results indicated that LUCC in the HRB exerted remarkable impacts on the regional surface energy and water balance, which was characterized by significant spatiotemporal variance, and the latent heat flux was higher than sensible heat flux in summer, while it was on the contrary in winter. Besides, the simulation results showed that the conversion from grassland to barren or sparsely vegetated land led to the most significant changes in the latent, sensible and total heat flux in all seasons in comparison to other types of land use/cover dynamics. This indicated that grassland degradation which was one of the most severe ecological and environmental problems in the HRB, exerted the most significant impacts on the surface energy balance. By contrast, the conversion from barren or sparsely vegetated land to water area led to the slowest and the minimum variation of heat flux in the whole year.

The simulation results in this study also indicated that the conversion from grassland to barren or sparsely vegetated land decreased the available energy for evapotranspiration, which correspondingly elevated the runoff. In other words, the evapotranspiration in the HRB was mostly controlled by the energy availability. Besides, the simulation results showed that effects of grassland degradation on the water balance are more prominent in summer and winter than in the other seasons. In addition, severe droughts can have significant influence on the surface soil moisture and plant growth and consequently greatly affect the latent heat flux. Therefore, it is necessary to consider the soil water conditions in the analysis of the effects of LUCC on albedo, energy and water balances at large scales. In addition, the simulation results in the four selected case study areas in the HRB showed that there were profound impacts of LUCC on the water balance, and the energy balance and the water balance interacted with each other. Therefore we put forward a suggestion of shifting the water balance by LUCC to improve the water management, which can shed light on the land use planning to offset the LUCC-induced negative impacts on the surface energy and water balances.

\section{Conflicts of Interest}

The authors declare that there is no conflict of interests regarding the publication of this article.

\section{Acknowledgements}

This research was financially supported by the major research plan of the National Natural Science Foundation of China (Grant No. 91325302), the National Natural Science Funds of China for Distinguished Young Scholar (Grant No. 71225005), and National
Key Programme for Developing Basic Science in China (Grant No. 2010CB950900). Also, the authors would like to thank Enjun Ma, Yongwei Yuan and Tao Zhang for their advice and assistant in the model simulation and the illustration drawing.

\section{References}

Anav, A., Ruti, P., Artale, V., Valentini, R., 2010. Modelling the effects of land-cover changes on surface climate in the Mediterranean region. Climate Res. (Open Access for articles 4 years old and older) 41, 91.

Ardli, E.R., Wolff, M., 2009. Land use and land cover change affecting habitat distribution in the Segara Anakan lagoon, Java, Indonesia. Reg. Environ. Change 9, 235-243.

Bormann, H., Breuer, L., Gräff, T., Huisman, J.A., 2007. Analysing the effects of soil properties changes associated with land use changes on the simulated water balance: a comparison of three hydrological catchment models for scenario analysis. Ecol. Model. 209, 29-40.

Boulain, N., Cappelaere, B., Séguis, L., Favreau, G., Gignoux, J., 2009. Water balance and vegetation change in the Sahel: a case study at the watershed scale with an eco-hydrological model. J. Arid Environ. 73, 1125-1135.

Chen, F., Dudhia, J., 2001. Coupling an advanced land surface-hydrology model with the Penn State-NCAR MM5 modeling system. Part I: Model implementation and sensitivity. Monthly Weather Rev. 129, 569-585.

Chen, Y., Zhang, D., Sun, Y., Liu, X., Wang, N., Savenije, H.H., 2005. Water demand management: a case study of the Heihe River Basin in China. Phys. Chem. Earth, Parts A/B/C 30, 408-419.

Deng, X., Huang, J., Rozelle, S., Uchida, E., 2006. Cultivated land conversion and potential agricultural productivity in China. Land Use Policy 23, 372-384.

Deng, X., Jiang, Q.o., Su, H., Wu, F., 2010. Trace forest conversions in Northeast China with a 1-km area percentage data model. J. Appl. Remote Sens. 4, 041893.

Deng, X., Han, J., Yin, F., 2012. Net energy, $\mathrm{CO}_{2}$ emission and land-based cost-benefit analyses of jatropha biodiesel: a case study of the Panzhihua Region of Sichuan Province in China. Energies 5, 2150-2164.

Deng, X., Zhao, C., Yan, H., 2013. Systematic modeling of impacts of land use and land cover changes on regional climate: a review. Adv. Meteorol. 2013.

Döll, P., Kaspar, F., Lehner, B., 2003. A global hydrological model for deriving water availability indicators: model tuning and validation. J. Hydrol. 270, 105-134.

Fettweis, X., 2007. Reconstruction of the 1979-2006 Greenland ice sheet surface mass balance using the regional climate model MAR. Cryosphere Discuss. 1, 123-168.

Fohrer, N., Haverkamp, S., Frede, H.G., 2005. Assessment of the effects of land use patterns on hydrologic landscape functions: development of sustainable land use concepts for low mountain range areas. Hydrol. Process. 19, 659-672.

Foley, J.A., DeFries, R., Asner, G.P., Barford, C., Bonan, G., Carpenter, S.R., Chapin, F.S. Coe, M.T., Daily, G.C., Gibbs, H.K., 2005. Global consequences of land use. Science 309, 570-574.

Gao, Y.H., Chen, F., Barlage, M., Liu, W., Cheng, G.D., Li, X., Yu, Y., Ran, Y.H., Li, H.Y. Peng, H.C., Ma, M.G., 2008. Enhancement of land surface information and its impact on atmospheric modeling in the Heihe River Basin, northwest China. J. Geophys. Res. - Atmos. 113.

Gerten, D., Schaphoff, S., Haberlandt, U., Lucht, W., Sitch, S., 2004. Terrestrial vegetation and water balance-hydrological evaluation of a dynamic global vegetation model. J. Hydrol. 286, 249-270.

Gregory, J.H., Dukes, M.D., Jones, P.H., Miller, G.L., 2006. Effect of urban soil compaction on infiltration rate. J. Soil Water Conserv. 61, 117-124.

Halihan, T., Wicks, C.M., Engeln, J.F., 1998. Physical response of a karst drainage basin to flood pulses: example of the Devil's Icebox cave system (Missouri, USA). J. Hydrol. 204, 24-36.

Huang, J., Zhan, J., Yan, H., Wu, F., Deng, X., 2013. Evaluation of the impacts of land use on water quality: a case study in the Chaohu Lake Basin. Sci. World J. 2013.

Jiang, Q.o., Deng, X., Zhan, J., He, S., 2011. Estimation of land production and its response to cultivated land conversion in North China Plain. Chin. Geograph. Sci. 21, 685-694.

Jothityangkoon, C. Sivapalan, M., Farmer, D., 2001. Process controls of water balance variability in a large semi-arid catchment: downward approach to hydrological model development. J. Hydrol. 254, 174-198.

Kanamaru, H., Kanamitsu, M., 2008. Model diagnosis of nighttime minimum temperature warming during summer due to irrigation in the California Central Valley. J. Hydrometeorol. 9, 1061-1072.

Kueppers, L.M., Snyder, M.A., 2012. Influence of irrigated agriculture on diurnal surface energy and water fluxes, surface climate, and atmospheric circulation in California. Climate Dyn. 38, 1017-1029.

Lambin, E.F., Meyfroidt, P., 2011. Global land use change, economic globalization, and the looming land scarcity. Proc. Natl. Acad. Sci. 108, 3465-3472.

Lenters, J.D., Coe, M.T., Foley, J.A., 2000. Surface water balance of the continental United States, 1963-1995: regional evaluation of a terrestrial biosphere model and the NCEP/NCAR reanalysis. J. Geophys. Res. 105 (22393-22322), 22425.

Li, K., Coe, M., Ramankutty, N., Jong, R.D., 2007. Modeling the hydrological impact of land-use change in West Africa. J. Hydrol. 337, 258-268.

Liu, J., Deng, X., 2011. Influence of different land use on urban microenvironment in Beijing City, China. J. Food, Agri. Environ. 9, 1005-1011.

Liu, J., Zhang, Z., Xu, X., Kuang, W., Zhou, W., Zhang, S., Li, R., Yan, C., Yu, D., Wu, S., 2009. Spatial patterns and driving forces of land use change in China in the early 21st century [J]. Acta Geograph. Sin. 12, 004 
Margono, B.A., Turubanova, S., Zhuravleva, I., Potapov, P., Tyukavina, A., Baccini, A., Goetz, S., Hansen, M.C., 2012. Mapping and monitoring deforestation and forest degradation in Sumatra (Indonesia) using Landsat time series data sets from 1990 to 2010. Environ. Res. Lett. 7, 034010.

Oke, T.R., 1982. The energetic basis of the urban heat island. Quart. J. R. Meteorol. Soc. $108,1-24$.

Ramankutty, N., Evan, A.T., Monfreda, C., Foley, J.A., 2008. Farming the planet: 1. Geographic distribution of global agricultural lands in the year 2000. Global Biogeochem. Cycles 22, GB1003.

Ramier, D., Boulain, N., Cappelaere, B., Timouk, F., Rabanit, M., Lloyd, C.R., Boubkraoui, S., Métayer, F., Descroix, L., Wawrzyniak, V., 2009. Towards an understanding of coupled physical and biological processes in the cultivated Sahel-1. Energy and water. J. Hydrol. 375, 204-216.

Romanowicz, A., Vanclooster, M., Rounsevell, M., La Junesse, I., 2005. Sensitivity of the SWAT model to the soil and land use data parametrisation: a case study in the Thyle catchment, Belgium. Ecol. Model. 187, 27-39.

Rwasoka, D.T., Gumindoga, W., Gwenzi, J., 2011. Estimation of actual evapotranspiration using the surface energy balance system (SEBS) algorithm in the Upper Manyame catchment in Zimbabwe. Phys. Chem. Earth, Parts A/B/C 36, 736-746.

Sahu, N., Singh, R., Kumar, P., Silva, R.V.D., Behera, S.K., 2013. La niña impacts on austral summer extremely high-streamflow events of the Paranaíba River in Brazil. Adv. Meteorol. 2013.

Sakai, R.K., Fitzjarrald, D.R., Moraes, O.L., Staebler, R.M., Acevedo, O.C., Czikowsky, M.J., Silva, R.d., Brait, E., Miranda, V., 2004. Land-use change effects on local energy, water, and carbon balances in an Amazonian agricultural field. Global Change Biol. 10, 895-907.
Schilling, K.E., Jha, M.K., Zhang, Y.K., Gassman, P.W., Wolter, C.F., 2008. Impact of land use and land cover change on the water balance of a large agricultural watershed: historical effects and future directions. Water Resour. Res. 44.

Seneviratne, S.I., Lüthi, D., Litschi, M., Schär, C., 2006. Land-atmosphere coupling and climate change in Europe. Nature 443, 205-209.

Seto, K.C., Fragkias, M., Güneralp, B., Reilly, M.K., 2011. A meta-analysis of global urban land expansion. PloS One 6, e23777.

Shindell, D.T., Schmidt, G.A., Mann, M.E., Rind, D., Waple, A., 2001. Solar forcing of regional climate change during the Maunder Minimum. Science 294, 21492152.

Sun, G., Noormets, A., Gavazzi, M., McNulty, S., Chen, J., Domec, J.-C., King, J., Amatya D., Skaggs, R., 2010. Energy and water balance of two contrasting loblolly pine plantations on the lower coastal plain of North Carolina, USA. Forest Ecol. Manage. 259, 1299-1310.

Twine, T.E., Kucharik, C.J., Foley, J.A., 2004. Effects of land cover change on the energy and water balance of the Mississippi River basin. J. Hydrometeorol. 5, 640-655.

van der Meijden, C.M., Veringa, H.J., Rabou, L.P., 2010. The production of synthetic natural gas (SNG): a comparison of three wood gasification systems for energy balance and overall efficiency. Biomass Bioenergy 34, 302-311.

Wu, F., Zhan, J., Yan, H., Shi, C., Huang, J., 2013. Land cover mapping based on multisource spatial data mining approach for climate simulation: a case study in the farming-pastoral ecotone of North China. Adv. Meteorol. 2013.

Yadav, P., Kapoor, M., Sarma, K., 2012. Land use land cover mapping, change detection and conflict analysis of Nagzira-Navegaon corridor, Central India using geospatial technology. Int. J. Remote Sens. GIS 1, 90-98. 